\title{
İşletmelerin Finansal Performansının Veri Zarflama Analizi Yöntemiyle Tespit Edilmesi: Borsa İstanbul'da İşlem Gören Enerji İşletmelerine Yönelik Bir Uygulama $^{1}$
}

\author{
DOI: $10.26466 /$ opus.746452 \\ * \\ Alirıza A $\breve{g}^{*}-$ Essref Kuloğlu** \\ * Dr. Öğr. Üyesi, Bayburt Üniversitesi, Bayburt/Türkiye \\ E-Posta: alirizaag@bayburt.edu.tr \\ ORCID: 0000-0001-5345-6245 \\ *Dr. Öğr. Üyesi, Bayburt Üniversitesi, Bayburt/Türkiye \\ E-Posta: esrefkuloglu@bayburt.edu.tr \\ ORCID: 0000-0001-8117-6224
}

\begin{abstract}
Öz
Ekonomik ve sosyal kalkınmanın gerçekleştirilmesinde önemli faktörlerden birisi enerjidir. Özellikle son yıllarda hızl nüfus artışı ve sanayileşmeye bağh olarak enerjiye olan ihtiyaç giderek artmıştır. Bununla birlikte küreselleşmeye bağlı olarak işletmeler arasındaki rekabet gittikçe acımasız bir hal almıştır. Küresel rekabet ortamında işletmelerin hayatta kalabilmeleri ve tatmin edici bir kâr marjı elde edebilmeleri için kaynakları etkin bir biçimde kullanmaları, minimum girdi ile maksimum çıktı elde etmeleri ve maliyetleri minimum seviyeye çekerek etkin bir biçimde kontrol etmeleri gerekmektedir. Bu doğrultuda işletmelerde yapilacak olan etkinlik analizi küresel rekabet ortaminda gerek işletmelerin performanslarının değerlendirilmesinde gerekse konumlarının belirlenmesinde önem arz etmektedir.

Bu doğrultuda yapılan çalışmanın amacı, Veri Zarflama Analizi (VZA) yöntemi ile 2019 yılında Borsa İstanbul (BIST)'da işlem gören enerji işletmelerinin finansal performanslarımı ve başka bir ifadeyle etkinliklerini ölçmektir. Bu amaç doğrultusunda, VZA yönteminin çıktı odaklı Charnes-Cooper-Rhodes (CCR) modeli ile 8 işletmenin etkinliği finansal tablolarından elde edilen 2 girdi ve 4 çıtı faktörü kullanılarak ölçülmüştür. Çalışma sonucunda enerji piyasasında faaliyet gösteren 5 işletme etkin bulunmuştur. Son olarak, etkin olmayan işletmelerin etkinlik düzeylerini artırabilmeleri için referans almalar gereken işletmeler belirlenmiş olup girdi ve çıktı değişkenleri ile ilgili gerekli potansiyel iyileştirme oranları tespit edilmiştir.
\end{abstract}

Anahtar Kelimeler: Enerji İşletmeleri, Finansal Performans, Etkinlik, Veri Zarflama Analizi

\footnotetext{
${ }^{1}$ Bu çalışma, 13-15 Mart 2020 tarihlerinde Tokat'ta düzenlenen 5. iKSAD Uluslararası Sosyal Bilimler Kongresi'nde sunulan "Işsletmelerin Finansal Performansının Veri Zarflama Analizi Yöntemiyle Tespit Edilmesi: BiST Enerji Piyasasında Bir Uygulama" adlı özet bildirinin genişletilmiş halidir.
} 


\title{
Determination of Financial Performance of Businesses By Data Envelopment Analysis: An Application for Energy Businesses Traded on Borsa Istanbul
}

\begin{abstract}
One of the important factors in the realization of economic and social development is energy. Especially in recent years due to rapid population growth and industrialization, the need for energy has gradually increased. However, due to globalization, competition between enterprises has become increasingly brutal. In order to survive and achieve a satisfactory profit margin in a globally competitive environment, businesses need to use resources effectively, achieve maximum output with minimum input, and effectively control costs by minimizing costs. In this respect, efficiency analysis to be conducted in enterprises is important both in evaluating the performance of enterprises and determining their position in the global competition environment.

The purpose of this study is to measure financial performance and efficiency of energy businesses listed on Borsa Istanbul (BIST) in 2019 by using Data Envelopment Analysis (DEA). For this purpose, the efficiency of 8 businesses with the output-oriented Charnes-Cooper-Rhodes (CCR) model of DEA method was measured by using 2 input and 4 output factors obtained from financial statements. As a result of the study, 5 businesses operating in the energy market were found to be effective. Finally, the businesses that should be referenced in order to increase the efficiency levels of ineffective businesses were identified and the necessary potential improvement rates related to input and output variables were determined.
\end{abstract}

Keywords: Energy Businesses, Financial Performance, Efficiency, Data Envelopment Analysis 


\section{Giriş}

Ekonomik açıdan stratejik öneme sahip olan enerjiye yönelik talep sanayileşme, teknolojik gelişmeler ve hızlı nüfus artışı gibi nedenlerle her geçen gün artmaktadır. Dolayısıyla enerji sektöründe faaliyet gösteren işletmelerin kıt olan doğal kaynakları etkin bir biçimde kullanarak minimum girdi ile maksimum çıktı elde etmeleri gerekmektedir. Bu doğrultuda asıl amacı işletmelerin ortaya koyduğu amaçların gerçekleşme derecesini ölçmek olan performans ölçümü işletmeler açısından önem arz etmektedir (Martin, 1997, s.435).

Küresel rekabet ortamında işletmelerin kaynakları etkin kullanıp kullanmadıklarını tespit etmede aynı sektör içerisinde benzer girdileri kullanarak benzer çıtılar üreten işletmelerin performansları önemli bir göstergedir. Bu doğrultuda Veri Zarflama Analizi Yöntemi (VZA), işletmelerin faaliyet gösterdikleri sektörde göreli etkinlik düzeylerini tespit etmede kullanılan bununla birlikte etkinlik düzeyleri düşük olan işletmeler için etkinliklerini artırabilmeleri için gerekli olan potansiyel iyileştirme oranlarını belirleyen bir yöntemdir (Özçelik ve Avc1, 2019, s.1012). VZA yöntemi nonparametrik bir model olmakla birlikte ilk olarak 1978 yılında ilk olarak Charnes, Cooper ve Rhodes (CCR) tarafından ayn sektörde faaliyet gösteren ve karar verme birimi (KVB) adlandırılan sistemlerin göreceli performanslarını (etkinliklerini) tespit etmek amacı ile geliştirilmiştir (Özden, 2008, s.169).

Çalışmada, BİST' te işlem gören enerji işletmelerinin 2019 yılı verileri kullanılarak bu işletmelerin etkinlik düzeyleri tespit edilmeye çalışılacaktır. Bu doğrultuda öncelikle literatür incelemesi yapılmış olup, daha sonra VZA yöntemine kısaca değinilmiştir. Uygulama aşamasında araştırmaya konu olan enerji işletmelerinin finansal performansları tespit edilmeye çalışılmıştır. Böylelikle hangi enerji işletmesinin etkin hangi enerji işletmelerinin etkin olmadığ 1 belirlenmiştir. Daha sonra araştırmaya konu olan enerji işletmeleri ile ilgi olarak genel bir değerlendirme yapılmış olup, etkinlik düzeyleri düşük olan işletmelerin etkinliklerini artırabilmeleri için gerekli olan potansiyel iyileștirme oranları tespit edilmiştir.

\section{Literatür}

Enerji sektöründeki firmaların etkinliğini ortaya koymak amacıyla veri zarflama analizi (VZA) anlamında yapılan çalışmaların büyük kısmını elektrik 
üretim tesisleri üzerinde yapılan çalışmalar oluşturmaktadır. Diğer yandan 1990'lu yıllardan itibaren ise VZA elektrik dağıtım sektörü kıyaslaması için de yaygın şekilde kullanılmaya başlanmıştır. 2000'li yıllarda ise enerji etkinliğinin ölçümü için VZA yöntemlerinin kullanımının arttı̆̆ görülmekte ve yapılan çalışmaların bölgesel ya da uluslararası ölçekte olduğu görülmektedir. Çalışmalarda genel olarak çıktı olarak gayri safi yurtiçi hasılanın, girdi olarak ise sermaye birikimi, işgücü, nüfus, enerji tüketimi gibi değişkenlerin kullanıldığı görülmektedir. Bu anlamda son yıllarda yapılan bazı çalışmalar aşağıda incelenmektedir.

Nemoto ve Goto (2003) çalışmalarında Japon elektrik tesislerinin üretimde dinamik etkinliğini veri zarflama analizi ile ölçmüştür. Çalışmanın veri setini, 1981-1995 dönemi için özel mülkiyete ait dokuz Japon elektrik tesisinin toplam 135 gözlemi oluşturmaktadır. Çalışmada analizin çıtısı, endüstriyel elektrik kullanımı ve hane halkı elektrik kullanımıdır. Analizde girdi olarak ise yakıt ve işgücünün yanında üretim tesisleri, iletim tesisleri ve dağıtım tesisleri olarak üç yarı-sabit girdi de kullanılmıştır. Çalışmanın sonuçlarına göre Japon elektrik tesisleri değişken girdilerinin kullanımında etkin iken, yarı-sabit değişken kullanımında ise etkin değildir.

Özyiğit, Serarslan ve Karsak (2008) çalışmalarında petrol, kömür, doğalgaz v.d. enerji kaynak alternatiflerinin etkinliğinin ölçülmesi için Bulanık VZA yöntemi kullanılmıştır. Çalışmadaki analiz için kullanılan enerji kaynaklarının performans analizindeki girdiler, birim elektrik üretimi için indirgenmiş maliyet ve karbondioksit v.d. gaz salınımlarıdır. Çıktılar ise sürdürülebilirlik, güvenilirlik ve uyumluluk olarak saptanmıştır. Çalışmada rüzgar enerjisi en etkin enerji kaynağı olarak bulunmuştur. Etkinlik sıralamasında ikinci sırada doğalgaz ve üçüncü sırada hidrolik enerjidir. Bu anlamda çalışmaya göre özellikle rüzgar ve hidrolik enerji, enerji üretiminde etkinlikleri ve Türkiye için kullanım potansiyeline sahip olması ile önem verilmesi gereken kaynaklardandır.

Ulucan ve Atıcı (2010) çalışmalarında Türkiye elektrik sanayinde yer alan 20 adet dağıtım şirketi VZA ile değerlendirmişlerdir. Çalışmada Türkiye'de yer alan elektrik dağıtım şirketlerinin etkinlik ölçümleri 5 adet girdi (hat uzunluğu, işgücü, işletme giderleri, kurulu güç ve sistem kayıpları) ve 2 adet çıktı (satılan güç ve müşteri sayısı) ile analiz edilmektedir. Burada kullanılan veriler 2006 yılına aittir. Çalışmada elde edilen sonuçlara göre 9 adet elektrik dağıtım firmasının etkinlik skorları girdi odaklı VZA yöntemine göre 1'e eşit 
yani etkin sınırdadır. Makalede yapılan bir diğer analiz ölçüt odaklı VZA'dır. Buna göre de 8 adet şirket etkin sınırda yer almaktadır. Girdi odaklı VZA yönteminde etkin olan Toroslar EDAŞ, ölçüt odaklı VZA'ya göre etkin sinırda yer almamaktadır.

Sueyoshi ve Goto (2012) çalışmalarında enerji firmalarının etkin ve etkin olmayan şeklinde gruplandırmayı ve verimlilik temelli sıralamasını ortaya koymayı amaçlamaktadır. Çalışmada Japon elektrik sisteminin devlet egemen sistemde liberalleşmeye geçişte faaliyet performansının nasıl etkilendiği incelenmektedir. Çalışmada 2005-2009 arası dönemdeki satılan elektrik tutarı ve toplam müşteri sayısı çıktı olarak kullanılırken, üretim için gerekli varlık toplamı, iletim için gerekli varlık toplamı, dağıtım için gerekli varlık toplamı, işçilik maliyeti dışında toplam faaliyet maliyeti ve çalışan sayısı ise girdi olarak kullanılmaktadır. Sonuçlara göre çalışmada enerji firmalarının VZA analizi ile etkinlik skorları verilerek en verimli ve en verimsiz firmalar belirlenmektedir. Yine sonuçlara göre liberalleşme nedeniyle elektrik enerjisi sektöründe henüz büyük bir değişikliğin olmadığı görülmektedir. Çalışmadaki bir başka hipotezinin testinin sonuçlarına göre ise Japon elektrik firmaları performanslarını artırmak için farklı stratejiler oluşturmaktadırlar.

Emre (2014) çalışmasında Temmuz 2013 itibariyle faaliyette bulunan RES'lerin etkinliklerini değerlendirmek amacıyla rüzgar hızı, rüzgar kapasite faktörü gibi lokasyona bağlı faktör verileri ile üretim, kapasite kullanımı, yıllık kazanç, tesis kurulumu ve şebeke bağlantı maliyetleri gibi verileri kullanmaktadır. Çalışmada girdi ve çıktı yönlü VZA yöntemlerin analizi sonucunda, 61 RES içinde 3 ile 18 arasında değişen farklı sayıda RES'lerin etkin olduğu belirlenmiştir.

Taşköprü (2014) çalışmasında Avrupa Birliği (AB)'ne üye 29 ülkenin enerji verimliliklerini ve göreli etkinliklerini, klasik VZA ve Kategorik VZA yöntemleri ile saptamaya çalışmıştır. Bunun için çalışmada kullanılan 2010 yılına ait çeşitli veriler $A B^{\prime}$ nin resmi istatistik kurumu olan EUROSTAT'tan elde edilmiştir. Çalışmada girdi ve çıktı değişkenleri olarak elektrik, kömür ve linyit, ham petrol, doğalgaz v.b. her türlü enerji türü ile enerji ihracatı ve ithalatı rakamları kullanılmıştır. Çalışmada ülkeler kredi notlarına göre kategorilere ayrılmaktadır. Böylece tüm karar verici birimlerin eşit biçimde değerlendirildiği klasik VZA yöntemine göre etkin olmayan bazı ülkelerin, kategorik değişken olarak kredi derecelerine göre değerlendirildiği kategorik VZA yöntemine göre etkin oldukları görülmektedir. 
Deliktaş ve Gürel Günal (2016) çalışmalarında 8 alt-orta gelir grubundaki, 9 üst-orta gelir grubundaki ve 20 yüksek gelir grubunda yer alan ülkelerin enerji kullanımındaki etkinliklerini VZA ile ölçmüşlerdir. 1991-2011 zaman aralığının kullanıldığı çalışmada enerji kullanımındaki etkinlik, geleneksel bir oran olan gayrisafi yurtiçi hasılanın içindeki bir pay olarak kullanılmamıştır. Bu orana yeni bir yaklaşım olarak çalışmada enerji kullanımı, gayrisafi yurt içi hasılanın, arsa alanı, nüfus ve karayolunun bir fonksiyonu olarak ele almıştır. Çalışmanın sonuçlarına göre yüksek gelir grubunda yer alan ülkelerin, düşük-orta ve yüksek-orta gelir seviyesinde yer alan ülkelere göre enerji verimliliği daha yüksek bulunmuştur.

Özdemir (2016) çalışmasında Türkiye' de bulunan 22 rüzgar enerji santrali (RES), karar verici birim olarak seçilmiştir. Çalışmada, RES kurulu gücü, RES'te tam zamanlı çalışan sayısı ve RES hesaplanan ortalama yıllık enerji üretimi 3 girdi iken RES gerçek enerji üretimi ise tek çıktıdır. Analizde çıktıya yönelik VZA modeli kullanılarak 2013, 2014 ve 2015 yılındaki RES'lerin göreceli etkinlikleri hesaplanmıştır. Çalışmanın uygulama sonuçlarına göre, çıktıya yönelik analizlerden birisine göre 2013, 2014 ve 2015 yıllarında 4 RES etkin bulunurken bir başka çıtıya yönelik analize göre 6 adet RES etkin bulunmuştur.

Eroğlu ve Seçkiner (2017) çalışmalarında rüzgar santrallerinin etkinliklerini belirlemeyi, etkinlik kayıplarını tespit etmeyi ve hangi rüzgar türbinlerine bakım yapılması gerektiğini ortaya koymayı amaçlamışlardır. Bu amaç doğrultusunda 2013 Ocak-2014 Aralık ayları için rüzgar santrallerinde bulunan 14 türbin için girdiye yönelik VZA ve Malmquist Toplam Faktör Verimlilik Endeksi (MTFV) modelleri kullanılmıştır. Çalışmada girdi olarak aylık jeneratör devri, rotor devri ve rüzgar hızı kullanılırken çıktı olarak ise üretilen aylık güç ortalaması kullanılmıştır. Çalışma sonucuna göre Ocak 2013'de bir rüzgar türbini en etkin iken aynı santraldeki diğer türbinler etkin değildir. Yine çalışmada 4 adet türbinin en büyük etkinlik ortalamasına sahip olduğu ve her iki yılda da etkinsiz olarak bulunan ve önemli bir performans kaybına sahip bir türbinin de bulunduğu sonucuna ulaşılmıştır.

Aydın Yenioğlu ve Ateş (2019) çalışmalarında Türkiye ve 2020 yenilenebilir enerji kullanımında hedeflerine ulaşmış 7 Avrupa ülkesinin 2015 ve 2016 yılları içindeki teknik ve ölçek etkinliklerini VZA ile hesaplamışlardır. 2020 yılına kadar yenilenebilir enerji üretim şeklini yerel kaynaklara çevirmeyi amaçlayan Türkiye, 2023 yılına kadar ise toplam enerji üretiminin \%30'unu 
yenilenebilir enerjiden karşılamayı hedeflemektedir. Bu amaçla çalışmada Avrupa'nın toplam enerji tüketiminden payın $\% 20$ ve yine enerji verimliliğini \%20'ye çıaran Avrupa ülkelerinden 7 tanesi karar verme birimi olarak seçilmiştir. Sonuçlara göre Türkiye 2015 ve 2016 yıllarında, Avrupa'nın 2020 hedeflerine ulaşmış ülkeleri ile kıyaslandığında sayısal olarak yatırım, tüketim ve GSYH anlamında uzakta kalmıştır. Bu anlamda çalışmaya göre Türkiye'nin yenilenebilir enerji tüketiminin gelişmiş ülkeler seviyesinde olmadığı ve yenilenebilir enerji yatırımlarının yeterli seviyede olmadığı söylenmektedir.

Adibfar (2019) çalışmasında Türkiye'de kurulu rüzgar santrallerinin verimliliklerini araştırmak için iki aşamalı VZA ve Tobit regresyon yöntemlerini kullanmıştır. Araştırmada üç girdi ve iki çıktı kullanılarak girdi ve çıktı odaklı 4 farklı VZA modeli kullanılmıştır. Çalışma sonuçlarına göre 2017 yılında rüzgar santrallerinin $\% 40 \prime 1$ tercih edilen seviyelerde çalışmaktadır. Diğer yandan çalışmada rüzgar santrallerinin $\% 42$ 'sinin yeni tesisler ekleme suretiyle işletme seviyesini artırması ve $\% 46$ 'sının ise fazla yapılan yatırımlar nedeniyle kapasitelerini azaltması gerektiği söylenmektedir.

\section{Araştırmanın Amacı ve Yöntemi}

Araştırmanın amacı, Veri Zarflama Analizi (VZA) yöntemi ile 2019 yılında Borsa İstanbul (BİST)'da işlem gören 8 adet enerji işletmesinin finansal performanslarını ölçmektir. Bu amaç doğrultusunda, VZA yönteminin çıktı odaklı Charnes-Cooper-Rhodes (CCR) modeli ile 8 işletmenin etkinliği, finansal tablolarından elde edilen 2 girdi ve 4 çıktı faktörü kullanılarak ölçülmektedir.

\section{Veri Zarflama Analizi (VZA)}

Veri Zarflama Analizi, üretilen mal ve hizmet bakımından birbirlerine benzer yapıdaki karar verme birimlerinin etkinliklerinin kıyaslanması ve göreli etkinliklerinin ölçülmesi için oluşturulmuş doğrusal programlama tabanlı parametrik olmayan bir ölçüm yöntemidir (Düzgün, 2011, s.92). Veri zarflama analizinde göreli etkinlikleri ölçmek için karar verme birimleri homojen olmalıdır. Bu analizin en önemli özelliklerinden bir tanesi çoklu girdi ve çoklu çıktı ortamında analiz yapılmasıdır (Yıldırım, Önder, 2018, s.201). 
VZA modelleri üretim süreci anlamında "girdiye yönelik" veya "çıttıya yönelik" olabilirler. Girdiye yönelik, çıktıyı en az girdi ile üretmek anlamındadır. Çıktıya yönelik ise belirli bir girdi ile en fazla çıtının üretilmesi amaçlanmaktadır. Bu anlamda çıtıya yönelik modellerde girdilere müdahale edilmeksizin çıktıların artıılması mümkündür (Aydın Yenioğlu ve Ateş, 2019, s.865).

VZA, elde edilen verilere dayalı olarak en iyi performans gösteren karar verme birimlerinden oluşan bir teknik etkinlik sınırı tanımlayarak bu sınırı bir referans kabul etmektedir. Bu yöntem ile karar birimlerinin bu sınıra olan uzaklıkları ölçülmekte ve bu sınır kullanılarak etkin olmayan işletmelerin etkin hale gelmeleri için yapmaları gereken değişiklikler gösterilmektedir. Yöntemde etkinlik sınırı etkin karar birimlerinin doğrusal kombinasyonu alınarak saptanmakta ve bu karar birimleri "hedef birimler" olarak adlandırılmaktadır. Etkin olmayan karar birimleri etkinlik sınırına etkin olanlara benzemeye çalışarak yaklaşacaklardır (Düzgün, 2011, s.92-93).

VZA yönteminde iki tane kısıt bulunmaktadır. Bu kısıtlardan ilki hiçbir ağırlığın negatif değer taşımaması, ikinci kısıt ise analize konu olan diğer karar birimlerine de uygulandığında hiçbir karar biriminin 1'i aşmamasıdır. Yöntemde bu kısıtlar ile her karar birimi girdi ve çıtılarının istenildiği şekilde ağırlıklandırılması mümkündür (Çelik, 2016, s.73).

\section{Karar Verici Birimlerin (KVB'lerin) Belirlenmesi}

VZA yönteminin uygulanabilmesinin ön koşulu, benzer kararların uygulandığı ve benzer organizasyonel yapıya sahip olan Karar Verici Birimlerin (KVB’lerin) seçilmesidir (Özçelik ve Avcı Öztürk, 2019, s.1021). KVB’lerin etkinliğinin tespit edilebilmesi için girdi ve çıktı olarak kullanılacak değişkenlerin tespit edilmesi gerekmektedir (Kula ve Özdemir, 2007, s.61). Bununla birlikte çalışmanın güvenilirliğinin yüksek olabilmesi için KVB sayısının belirlenmesinde genel kabul gören kısıt; en az $\mathrm{m}+\mathrm{p}+1$ tane KVB seçilmesidir. Burada $\mathrm{m}$ seçilen girdi sayısını gösterirken, $\mathrm{p}$ çıkı sayısını göstermektedir (Boussofiane, Dyson ve Thanassoulis, 1991, s. 15). Yapılan bu çalışmada KVB'ler, 2019 yılında BİST'te işlem gören 8 enerji işletmesidir. Çalışmada, 2 girdi ile 4 çıtı kullanıldığından minimum 2+4+1=7 KVB analize katılmalıdır. Çalışmada 8 KVB seçildiğinden analizin güvenilir olduğu söylenebilir. Aşağıdaki tabloda araştırmaya konu olan enerji işletmesi belirtilmiştir. 
Tablo 1. Araştırmaya Konu Olan İşletmeler

\begin{tabular}{lll}
\hline & İsslem Kodu & İşletme Adı \\
\hline $\mathbf{1}$ & AKENR & Akenerji Elektrik Üretim A.Ş. \\
\hline $\mathbf{2}$ & AKSEN & Aksa Enerji Üretim A.Ş. \\
\hline $\mathbf{3}$ & AKSUE & Aksu Enerji Ve Ticaret A.Ş. \\
\hline $\mathbf{4}$ & AYEN & Ayen Enerji A.Ş. \\
\hline $\mathbf{5}$ & ENJSA & Enerjisa Enerji A.Ş. \\
\hline $\mathbf{6}$ & NATEN & Naturel Yenilenebilir Enerji Ticaret A.Ş. \\
\hline $\mathbf{7}$ & ODAS & Odaş Elektrik Üretim Sanayi Ticaret A.Ş. \\
\hline $\mathbf{8}$ & ZOREN & Zorlu Enerji Elektrik Üretim A.Ş. \\
\hline
\end{tabular}

\section{Girdi ve Çıktı Değişkenlerinin Belirlenmesi}

Çalışmada kullanılan veriler BİST'te işlem gören 8 adet enerji işletmesinin 2019 yılı dönem sonu verilerinden elde edilen finansal oranlar olmakla birlikte bu oranlar analize konu olan işletmelerin Kamuyu Aydınlatma Platformu (KAP)'nun internet sayfasında yayınlanan finansal tablolarından (bilanço ve gelir tablosu) elde edilmiştir. Çalışmaya konu olan enerji işletmeleri için tespit edilen girdi ve çıktı değişkenleri aşağıdaki tabloda belirtilmiştir.

Tablo 2. Çalışmada Kullanılan Girdi ve Çıktı Değişkenleri

\begin{tabular}{ll}
\hline Girdiler & Çıktılar \\
\hline Cari Oran & Duran Varlıklar / Aktif \\
\hline Özsermaye / Maddi Duran Varlıklar & Esas Faaliyet Kâr Marjı \\
\hline & Aktif Kârllı̆̆ı \\
\hline & Özsermaye Kârllı̆̆ı̆ı \\
\hline
\end{tabular}

\section{Bulgular}

Çalışmanın bu kısmında araştırma kapsamında ele alınan 8 işletmenin VZA yöntemine göre etkinlikleri tespit edilecek ve iyileştirme oranları hesaplanacaktır.

KVB'lerin Etkinlik Dereceleri ile Etkin Olmayan KVB'ler için İyileştirme Oranlarınin Hesaplanması

Çalışmada VZA yönteminin çıktıya yönelik CCR modeli kullanılarak çalışmaya konu olan enerji işletmelerinin etkinlikleri tespit edilmeye 
çalışılmıştır. Çalışmada EMS 1.3 paket programı kullanılarak enerji işletmelerinin etkinlik dereceleri analiz edilmiştir. Yapılan analiz sonucu hesaplanan 2019 yılına ilişkin etkinlik skorları aşağıdaki tabloda belirtilmiştir.

Tablo 3. 2019 Yılında BİST'te İşlem Gören Enerji İşletmelerinin Çıktıya Yönelik CCR Modeli Etkinlik Skorlarn (\% cinsinden)

\begin{tabular}{ll}
\hline İşletmeler & Etkinlik Skoru \\
\hline AKENR & 100,00 \\
\hline AKSEN & 114,09 \\
\hline AKSUE & 100,00 \\
\hline AYEN & 100,00 \\
\hline ENJSA & 100,00 \\
\hline NATEN & 122,98 \\
\hline ODAS & 100,04 \\
\hline ZOREN & 100,00 \\
\hline Tüm İşletmelerin Etkinlik Ortalaması & $\mathbf{1 0 4 , 6 3}$ \\
\hline Etkin Bulunan İsletme Sayısı & $\mathbf{5}$ \\
\hline Tüm İşletmelerin Etkinlik Yüzdesi & $\mathbf{6 2 , 5}$ \\
\hline
\end{tabular}

2019 yılına ilişkin çıktıya göre VZA'nın CCR modeli sonucuna göre etkinliği \% 100'e eşit olan 5 işletme (Ak Enerji, Aksu Enerji, Ayen Enerji, Enerjisa Enerji ve Zorlu Enerji) tespit edilmiştir. Enerji işletmelerinin ortalama etkinlik skoru, \% 104,63'tür. Tüm enerji işletmelerinin etkinlik yüzdesi ise \% 62.5 olarak hesaplanmıştır.

VZA yöntemi yapılan analiz sayesinde etkinlik düzeyleri düşük olan KVB'lerin etkinlik düzeylerini artırabilmeleri için çeşitli hedefler belirlenebilmektedir. Bu bağlamda araştırmaya konu olan ve 2019 yılında etkin olmayan enerji işletmeleri için potansiyel iyileştirme oranları hesaplanmış olup bu oranlar aşağıdaki Tablo 4'te belirletmiştir. Analiz sonuçlarına göre etkin olmayan işletmelerin daha etkin olmaları için hangi değişkenlerin değerinin ne kadar azaltılması veya ne kadar arttırılması gerektiği tespit edilmiştir.

Tablo 4. 2019 Yılında CCR VZA Modeliyle Etkin Olmayan Enerji İşletmeleri İçin Hedef Değerler, İyileştirme Oranlan ve Referans Kümeleri

\begin{tabular}{|c|c|c|c|c|c|c|}
\hline \multirow[t]{2}{*}{ İşletme } & \multicolumn{2}{|c|}{ Değişkenler } & Gerçekleşen & \multirow{2}{*}{$\begin{array}{l}\text { Hedef } \\
0,86\end{array}$} & \multirow{2}{*}{$\begin{array}{c}\text { İyileştir } \\
\text { me (\%) }\end{array}$} & \multirow{2}{*}{$\begin{array}{l}\text { Referans } \\
\text { Kümesi } \\
\end{array}$} \\
\hline & Girdile & Cari Oran & 0,86 & & & \\
\hline \multirow{4}{*}{$\begin{array}{l}z \\
\text { 至 } \\
\frac{2}{4}\end{array}$} & $\mathrm{r}$ & Özsermaye / Maddi Duran Varlıklar & 0,52 & 0,52 & 0,00 & \\
\hline & Çıktılar & Duran Varlıklar / Aktif & 58,93 & 133,84 & 1,27 & \\
\hline & & Esas Faaliyet Kar Marj1 & 19,16 & 54,63 & 1,85 & \\
\hline & & Aktif Karlılık & 2,51 & 2,87 & 0,14 & \\
\hline
\end{tabular}




\begin{tabular}{|c|c|c|c|c|c|c|}
\hline & & Özsermaye Karlılığı & 8,94 & 12,44 & 0,39 & $\begin{array}{l}\text { AKSUE } \\
\text { AYEN }\end{array}$ \\
\hline \multirow{6}{*}{ 㿿 } & \multirow{2}{*}{$\begin{array}{l}\text { Girdile } \\
\mathrm{r}\end{array}$} & Cari Oran & 1,16 & 1,03 & $-0,11$ & \multirow{6}{*}{$\begin{array}{l}\text { AKSUE } \\
\text { AYEN }\end{array}$} \\
\hline & & Özsermaye / Maddi Duran Varlıklar & 0,66 & 0,66 & 0,00 & \\
\hline & \multirow[t]{4}{*}{ Çıktılar } & Duran Varlıklar / Aktif & 73,67 & 174,39 & 1,37 & \\
\hline & & Esas Faaliyet Kar Marjı & 57,04 & 69,92 & 0,23 & \\
\hline & & Aktif Karlılık & 2,90 & 3,55 & 0,22 & \\
\hline & & Özsermaye Karlılı̆ğ & 6,37 & 15,69 & 1,46 & \\
\hline \multirow{6}{*}{ 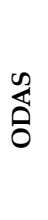 } & \multirow{2}{*}{$\begin{array}{l}\text { Girdile } \\
\mathrm{r}\end{array}$} & Cari Oran & 0,39 & 0,39 & 0,00 & \multirow{6}{*}{$\begin{array}{l}\text { AKENR } \\
\text { AYEN }\end{array}$} \\
\hline & & Özsermaye / Maddi Duran Varlıklar & 0,37 & 0,29 & $-0,23$ & \\
\hline & \multirow[t]{4}{*}{ Çıktılar } & Duran Varlıklar / Aktif & 85,96 & 85,71 & 0,00 & \\
\hline & & Esas Faaliyet Kar Marjı & 13,31 & 31,87 & 1,39 & \\
\hline & & Aktif Karlılık & $-1,94$ & 1,15 & $-1,59$ & \\
\hline & & Özsermaye Karlılı̆̆1 & $-7,14$ & $-6,61$ & $-0,07$ & \\
\hline
\end{tabular}

Potansiyel iyileştirme oranlarının incelendiğinde NATEN Enerji işletmesinin girdi değişkenlerinden cari oranı \%11 oranında azaltıp, çıktı değişkenlerinden duran varlık/aktif oranını \%1,37 oranında, esas faaliyet kâr marjını \%23 oranında, aktif kârlılığını \%22 oranında, özsermaye kârlılığını \%1,46 oranında artırdığı zaman aynı referans kümesinde yer alan AKSU ve ATEN Enerji gibi etkin hale gelecektir.

\section{Tartışma ve Sonuç}

Yeryüzündeki yaşamın devam edebilmesi açısından enerjinin önemi büyüktür. Dolayısıyla ekonomik ve sosyal kalkınmanın başrol oyuncularından olan enerjiye olan ihtiyaç her geçen gün gittikçe artmaktadır. Bununla birlikte küreselleşen dünyada işletmelerin acımasız rekabet ortamında hayatta kalabilmeleri ve rakiplerine karşı üstünlük sağlayabilmeleri açısından kaynakları etkin bir biçimde kullanarak performanslarını artırmaları önem arz etmektedir. Bu doğrultuda VZA yöntemi işletmelerin etkinliklerin ölçmede kullanılan bir yöntem olmakla beraber etkinlikleri düşük olan işletmelere etkinlik derecelerini artırabilmeleri için gerekli olan potansiyel iyileştirme oranlarının tespit edilmesine yarayan bir yöntemdir.

Yapılan bu çalışmada BİST'te işlem gören 8 adet enerji işletmesinin 2019 yılındaki etkinlik dereceleri parametrik olmayan VZA yaklaşımı kullanılarak ölçülmüştür. Yapılan analizde girdi değişkeni olarak Cari Oran, Özsermaye / Maddi Duran Varlıklar oranı kullanılırken çıktı değişkeni olarak Duran Varlıklar / Aktif, Esas Faaliyet Kâr Marjı, Aktif Kârlılığı, Özsermaye Kârlılığı kullanılmıştır. Çıktıya yönelik CCR modeli analiz sonucuna göre 2019 
yılında; Ak Enerji, Aksu Enerji, Ayen Enerji, Enerjisa Enerji ve Zorlu Enerji olmak üzere 5 işletme etkin bulunmuştur. Tüm enerji işletmelerinin etkinlik yüzdesi \%62,5'tir. Bununla birlikte etkinlik dereceleri düşük olan işletmeler için iyileştirme oranları tespit edilmiştir. Son olarak şunu söyleyebiliriz ki VZA yönteminde kullanılan girdi çıktı değişkenlerinin farklı olması farklı sonuçlar doğurabilir. Bu doğrultuda analizde kullanılan değişkenlerin belirlenmesinde gerek işletme yönetimi gerekse potansiyel yatırımciların görüşleri dikkate alınarak kullanılan değişkenler çeşitlendirilebilir. 
EXTENDED ABSTRACT

\title{
Determination of Financial Performance of Businesses By Data Envelopment Analysis: An Application for Energy Businesses Traded on Borsa Istanbul
}

\author{
Alirıza A ̆ - Eşref Kuloğlu \\ Bayburt University
}

In determining whether businesses use resources effectively in a global competitive environment, performances of businesses that produce similar outputs using similar inputs in the same sector are an important indicator. Accordingly, the Data Envelopment Analysis Method (DEA) is a method that is used to determine the relative activity levels in the sector in which businesses operate, however, it determines the potential improvement rates required for businesses with low efficiency levels to increase their effectiveness. Although DEA method is a nonparametric model, it was first developed in 1978 by Charnes, Cooper and Rhodes (CCR) in order to determine the relative performances (activities) of the systems operating in the same sector and called Decision Making Units.

In the study, the efficiency levels of these businesses will be tried to be determined by using the 2019 data of the energy businesses traded in BIST. In this direction, firstly, literature review was made and then DEA method was briefly mentioned. At the application stage, the financial performances of the energy companies subject to the research were tried to be determined. Thus, it has been determined which energy company is effective and which energy businesses is not. Then, a general evaluation was made with regard to the energy businesses subject to the research, and the potential improvement rates required for the businesses with low efficiency levels were determined to increase their efficiency.

According to the results of the literature review conducted in the study, studies on electricity generation facilities comprise the majority of the studies 
carried out in terms of data envelopment analysis (DEA) in order to reveal the efficiency of companies in the energy sector. On the other hand, since the 1990s, DEA has been widely used for the electricity distribution sector. In 2000s, it is seen that the use of DEA methods has increased for the measurement of energy efficiency and it is seen that the studies have been done on a regional or international scale. In the studies, it is seen that gross domestic product is used as output and variables such as capital accumulation, labor, population, energy consumption are used as input.

In this study, the aim is to measure the financial performance of 8 energy businesses traded on Borsa Istanbul (BIST) in 2019 with the Data Envelopment Analysis (DEA) method. For this purpose, the effectiveness of 8 businesses with the output-oriented Charnes-Cooper-Rhodes (CCR) model of DEA method is measured by using 2 inputs and 4 output factors obtained from the financial statements.

The prerequisite for the application of DEA method is the selection of Decision-Making Units (DMU) where similar decisions are applied and have a similar organizational structure. In order to determine the effectiveness of DMUs, the variables that will be used as input and output must be determined (Kula and Özdemir, 2007, p.61). However, in order for the reliability of the study to be high, the generally accepted restriction in determining the number of DMU; At least $\mathrm{m}+\mathrm{p}+1 \mathrm{DMU}$ is chosen. Here $\mathrm{m}$ indicates the number of inputs selected, while $\mathrm{p}$ shows the number of outputs (Boussofiane, Dyson and Thanassoulis, 1991, p. 15). In this study, DMUs are 8 energy businesses traded at BIST in 2019. In the study, since 2 inputs and 4 outputs are used, a minimum of $2+4+1=7$ DMU should be included in the analysis. Since $8 \mathrm{DMU}$ was chosen in the study, it can be said that analysis is reliable. These DMUs are Ak Energy, Aksa Energy, Aksu Energy, Ayen Energy, Enerjisa Energy, Natural Renewable Energy, Odaş Electricity Production and Zorlu Energy.

Although the data used in the study are the financial rates obtained from the end-2019 data of 8 energy companies traded at BIST, these rates are obtained from the financial statements (balance sheet and income statement) published on the Public Disclosure Platform of the companies subject to the analysis. . Inputs determined for the energy companies subject to the study; current ratio and equity / tangible assets ratio and outputs are fixed assets / 
assets ratio, main operating profit margin, asset profitability and equity profitability.

In the findings part of the study, the effectiveness of the 8 businesses considered within the scope of the research will be determined according to DEA method and the improvement rates will be calculated. In the study, the efficiency of the energy companies subject to the study was determined by using the output-oriented CCR model of DEA method. In the study, the efficiency levels of energy businesses were analyzed using EMS 1.3 package program. According to the output for 2019, 5 businesses (Ak Energy, Aksu Energy, Ayen Energy, Enerjisa Energy and Zorlu Energy), whose efficiency is equal to $100 \%$ according to the CCR model result, were determined. The average efficiency score of energy businesses is $104.63 \%$. The efficiency percentage of all energy companies was calculated as $62.5 \%$.

Thanks to the analysis made in DEA method, various targets can be determined in order to increase the effectiveness levels of DMUs with low efficiency levels. In this context, potential improvement rates have been calculated for the energy companies that are the subject of the research and are not effective in 2019. According to these rates, NATEN Energy Company decreased its current ratio from input variables by $11 \%$ and increased the asset / asset ratio from output variables by $1.37 \%$, its main operating profit margin by $23 \%$, asset profitability by $22 \%$ and equity profitability by $1.46 \%$. time will become effective like AKSU and ATEN Energy in the same reference set.

\section{Kaynakça / References}

Adibfar, B. (2019). Productive efficiency of Turkish wind farms: a two-stage data envelopment analysis. Yayımlanmamış yüksek lisans tezi. İhsan Doğramacı Bilkent Üniversitesi, Ankara.

Aydın Yenioğlu, Z., ve Ateş, V. (2019). Yenilenebilir enerji kullanımındaki göreceli etkinliklerin veri zarflama analizi ile değerlendirilmesi: Türkiye ve bazı Avrupa ülkeleri örneği. Politeknik Dergisi, 22(4), 863-869.

Boussofiane, A., Dyson, R. ve Thanassoulis, E. (1991). Applied data envolopment analysis. European Journal of Operational Research, 52(1), 1-15.

Çelik, M. K. (2016). Turizm sektöründeki işletmelerinin etkinliklerinin veri zarflama analizi ile ölçülmesi. International Journal of Economic $\mathcal{E}$ Administrative Studies, 17. 
Deliktaş, E., ve Gürel Günal, G. (2017). Measurement of energy use efficiency in lower-middle, upper-middle and high income countries: A data envelopment analysis. Yönetim ve Ekonomi, 24(2), 407.

Düzgün, M. (2011). Veri zarflama analiziyle elektrik dağıtım şirketlerinin etkinlik ve verimlilik analizi. Yayımlanmamış Yüksek Lisans Tezi. Ankara Üniversitesi, Ankara.

Emre, T. (2014). Türkiye'deki rüzgar enerji santrallerinin (RES) göreli etkinliklerinin veri zarflama analizi (VZA) ile ölçümü. (Yayımlanmamış yüksek lisans tezi). Hacettepe Üniversitesi, Ankara.

Eroğlu, Y., ve Seçkiner, S. U. (2017). Rüzgâr çiftliklerinde veri zarflama analizi ve Malmquist endeksi yaklaşımları ile performans analizi. Pamukkale University Journal of Engineering Sciences, 23(1).

Kamuyu Aydınlatma Platformu [KAP]. (t.y). Ansayfa. 10.01.2020 tarihinde https://www.kap.org.tr/tr/Sektorler adresinden erişildi.

Kula, V. ve Özdemir, L. (2007). Çimento sektöründe göreceli etkinsizlik alanlarının veri zarflama analizi yöntemi ile tespiti. Afyon Kocatepe Üniversitesi İktisadi ve İdari Bilimler Fakültesi Dergisi, 9(1), 55-70.

Martin, R. (1997). Do we practise quality principles in the performance measurement of critical success factors?. Total Quality Management, 8(6), 429-444.

Nemoto, J. ve Goto, M. (2003). Measurement of dynamic efficiency in production: An application of data envelopment analysis to japanese electric utilities. Journal Of Productivity Analysis, 19(2-3), 191-210.

Özçelik, F., Avc Öztürk B. (2019). Girdi olarak maliyetlere yönelik veri zarflama analizi modelleri ile göreli etkinlik analizi, İşletme Araştrmaları Dergisi, 11(2), 1011-1028.

Özdemir, M.H. (2016). Veri zarflama analizi ile rüzgâr enerji santrallerinin etkinliklerinin karşılaştırılması. Yayımlanmamış doktora tezi. İstanbul Üniversitesi, İstanbul.

Özden, Ü. (2008). Veri zarflama analizi (VZA) ile Türkiye'deki vakıf üniversitelerinin etkinliğinin ölçülmesi. İstanbul Üniversitesi İşletme Fakültesi Dergisi, 37(2), 167185.

Özyiğit, T., Serarslan, M. N. ve Karsak, E. E. (2011). Türkiye'de elektrik üretimi için enerji kaynaklarını etkinliğinin değerlendirilmesi. ITTü Dergisi, 7(5).

Sueyoshi, T. ve Goto, M. (2012). Efficiency-based rank assessment for electric power industry: a combined use of data envelopment analysis (DEA) and DEAdiscriminant analysis (DA). Energy Economics, 34(3), 634-644. 
Taşköprü, V. (2014). Klasik veri zarflama analizi ile kategorik veri zarflama analizi modellerinin enerji verimliliği üzerinde karşılaştırmal incelenmesi. Yayımlanmamış yüksek lisans tezi. Mimar Sinan Üniversitesi, İstanbul.

Ulucan, A. ve Atıcı, K. B. (2010). Enerji ve çevre konularında parametrik olmayan etkinlik analizi ve Türkiye elektrik sanayii uygulaması. Hacettepe Üniversitesi İktisadi ve İdari Bilimler Fakültesi Dergisi, 28(1), 173-203.

Savaş, F. (2018). Veri zarflama analizi. B.F. Yıldırım ve E. Önder (Der.) Işsletmeciler, Mühendisler ve Yöneticiler için Operasyonel, Yönetsel ve Stratejik Problemlerin Çözümünde Çok Kriterli Karar Verme Teknikleri içinde (s. 201-227). Bursa: Dora Yayınevi.

\section{Kaynakça Bilgisi / Citation Information}

A $\breve{g}$, A. ve Kuloğlu, E. (2020). İşletmelerin finansal performansının veri zarflama analizi yöntemiyle tespit edilmesi:Borsa İstanbul'da işlem gören enerji işletmelerine yönelik bir uygulama. OPUS-Uluslararası Toplum Araştırmaları Dergisi, 16(Özel Sayı), 3756-3772. DOI: 10.26466/opus.746452 